4-1-2005

\title{
Advances in Graduate Nursing Education: Beyond The Advanced Practice Nurse
}

Sharon Radzyminski

Cleveland State University, s.radzyminski@csuohio.edu

Follow this and additional works at: https://engagedscholarship.csuohio.edu/nurs_facpub

Part of the Nursing Commons

How does access to this work benefit you? Let us know!

\section{Publisher's Statement}

NOTICE: this is the author's version of a work that was accepted for publication in Journal of Professional Nursing. Changes resulting from the publishing process, such as peer review, editing, corrections, structural formatting, and other quality control mechanisms may not be reflected in this document. Changes may have been made to this work since it was submitted for publication. A definitive version was subsequently published in Journal of Professional Nursing, 21, 2, March - April 2005 DOI\#10.1016/j.profnurs.2005.01.003

\section{Recommended Citation}

Radzyminski, Sharon, "Advances in Graduate Nursing Education: Beyond The Advanced Practice Nurse" (2005). Nursing Faculty Publications. 33.

https://engagedscholarship.csuohio.edu/nurs_facpub/33

This Article is brought to you for free and open access by the School of Nursing at EngagedScholarship@CSU. It has been accepted for inclusion in Nursing Faculty Publications by an authorized administrator of EngagedScholarship@CSU. For more information, please contact library.es@csuohio.edu. 


\title{
Advances in Graduate Nursing Education: Beyond the Advanced Practice Nurse
}

\author{
Sharon Radzyminski, PhD, JD, RN
}

I

N 1998 THE American Association of Colleges of Nursing (AACN) released their report on the essential elements of master's education for advanced practice roles in nursing. They based their comments, in part, on the work of Conrad, Haworth, and Miller (1993) who published a comprehensive review of graduate education entitled A Silent Success: Master's Education in the United States. Conrad et al. (1993) gave strong support to the important role that graduate education plays in developing a cadre of skilled professionals who make important contributions to the health, education, business, political, and social structure of the United
States. The profession of nursing was included among those identified as making significant contributions at the graduate level. It did not go unnoticed, however, that nursing graduate programs were very diverse in title, curriculum, clinical components, and educational experiences.

Graduate education has always provided a vehicle for advanced practice in nursing. Growing public acceptance and health-care systems interest in advanced practice nurses' ability to contribute to healthcare services has also created greater scrutiny of these clinicians, their utilization, skill and knowledge base, and their educational experiences. Policy makers expressed concern about the diversity represented in both the advanced practice nursing education programs and titling. Safriet (1992) provided an exquisite analysis of the legal and regulatory guidelines shaping advanced practice in nursing and criticized the divergent titling used to describe advanced practice nurses.

Master's programs in nursing have both benefited from and struggled with the diversity of program types, degree requirements, and program or degree proliferation. The greater concern for consumer confidence, quality graduate education, and clear outcomes mandate that a more coherent and consistent set of curriculum standards be articulated. AACN recognized these concerns initially and responded by advocating that the primary focus of the master's education program in nursing should be on the clinical role (AACN 1993, 1996). Since then, however, several reports (Buerhaus, Staiger \& Auerbauch, 2000; Institute of Medicine, 2003; Kimball \& O'Neill, 2002) have identified the intense concern over health-care outcomes related to the nursing shortage. These concerns extend to increasing the overall number of nurses and to creating a professional role that will attract individuals into the profession and provide clinical leadership in the health-care settings. It has been suggested (Kimball \& O'Neill, 2002) that graduate education in nursing must go beyond the clinical role and prepare nurses 
who can coordinate care in complex situations, be prepared for clinical leadership roles, educate a new generation of nurses, and implement outcome-based practice and quality improvement strategies.

\section{The Need to go Beyond the Clinical Role}

If advanced practice in nursing needs to go beyond the stereotypical role of patient assessment and direct care, the direction of this practice is in question. Currently, most graduate nursing programs includes aspects of education, advocacy, leadership, business, law, theory development, and research. The degree to which these elements are included in the curriculum and the focus of the program vary greatly and produce graduates that function at vastly different skill levels in any given area. A nurse prepared at the master's level not only needs to be able to serve important functions as an expert clinician but also as a faculty member in nursing education programs, a role model for novice nurses, an administrator overseeing the practice of nursing, or a researcher advancing the knowledge base for the profession. It is unrealistic to think that any one type of graduate program can prepare individuals to practice expertly in each of those roles.

In the past few years, the AACN has begun to move away from their strong stance that graduate education in nursing should focus primarily on the expert clinician. This is not interpreted to mean there is a decreased need or support for nurses with advanced clinical skills but that there is an emerging need for nurses to manage care on a microsystems level. To this respect, the AACN has proposed the clinical nurse leader (CNL) role that supplements and supports existing nursing roles. The AACN has emphatically stated that the new role is not administratively focused but rather one that prepares the nurse to function within a microsystem and assume accountability for healthcare outcomes for a specific group of clients (population-focused) within a unit or setting. This is accomplished through the assimilation and application of research-based information to design, implement, and evaluate client plans of care (AACN, 2004). In a profession already plagued with diversity of program types, it is not surprising that the introduction of this new role has created some defensive maneuvers from those who already educate nurses at the advanced practice level. Many existing graduate programs specialize in care of aggregates (population-focused) rather than individuals, or have educational, research, or management foci. There are several graduate programs that include courses in integrated information technologies, health-care policy, health-care finance, statistics, and research that claim their graduates can deliver cost effective, research-based plans of care. It can be expected, therefore, that existing programs for advanced practice, population-focused care, or business such as MSN/MBA question the need or the difference in curricula for programs that specifically aim their outcomes to be population, systems, or leadership oriented.

\section{Are Current Graduate Programs Sufficient to Meet Future Needs?}

The diversity of graduate nursing programs is immense. There are programs that educate clinical nurse specialists, nurse practitioners, community health specialists, public health nurse specialists, business or health-care administrative nurse specialists, or programs that advance the profession of nursing through theory development and research. It appears that every aspect of nursing is supported by an advanced educational program. In light of this, however, more individuals die each year at the hands of health-care professionals than in motor vehicle accidents or by such diseases as breast cancer or AIDS (Institute of Medicine, 2003). A large number of these fatalities are specifically the result of nurse related errors. In addition, the nation is facing a significant nursing shortage that is predicted to impact the already fragmented nature of the healthcare delivery system and produce an even higher error rate. This is occurring at a time when the population is aging and an increased demand for services is predicted with a corresponding lack of financial resources. There are reports that indicate that individual plans of care that are either disease or wellness focused are expensive and inefficient over time if lifestyle changes, environmental changes, and public policy that support these changes are not aggressively sought (U.S. Department of Health and Human Services [DHHS], 2000).

It could be argued that graduate programs that educate geriatric nurse practitioners or clinical nurse specialists can meet the needs of the changing population; community health and public health clinical nurse specialists can respond to environmental issues and public policy; nurses with advanced skills in case management can improve quality of care while managing costs; nurses with advanced administrative or business degrees can provide supervision 
and leadership; and those with $\mathrm{PhDs}$ will lead the profession in theory development, research, and educate the next generation. It could also be argued that this system is expensive, narrow in focus, contributes to the fragmentation of care, and does not meet the needs of society or nursing (Kimball $\&$ O'Neill, 2002). What is missing is the nurse expert who can provide clinical leadership in or across all health-care settings, understands and can coordinate the diverse roles of nurses and other health-care workers, understands and then coordinates and evaluates care across units or systems in a costefficient manner, can interact at a colleague level to clinically manage at a systems level, and who can design, implement, and evaluate care strategies that impact the macrolevel trends in health status (lifestyle, attitudes, values, and behaviors). Does this mean that we no longer need clinical nurse specialists, nurse practitioners, and nurse administrators? No. What it means is that in a world of expanding technologies and complex societies, we need someone that understands the forces that drives health-care, including the health-care practices of the individual, who can coordinate, implement, or evaluate services at a systems level to ensure quality in a cost efficient manner. Without such individuals, systems eventually break down or become costly. The question remains whether nursing has sufficient number of these individuals. The AACN, after investigation of the question, seems to indicate that we do not.

\section{What Focus Should Graduate Education Programs in Nursing Take?}

If the goal is to produce a clinical leader with a systems perspective, how is the curriculum different from current clinical nurse specialist, community nurse specialist, or nurse administration programs? The answer is probably not what the program includes or excludes but rather which concepts are developed at the expert level.

The inclusion of public policy into the curriculum is one such concept that has been argued by Milio (2002) to have far greater impact on health care than any nurse-specific policy. Although health-care policy is introduced in many graduate nursing curricula, particularly in community and public health, nurses educated outside these programs may no longer be able to practice effectively without skill and knowledge related to community organizations, and the public policies that affect them (Donahue, 1997). This is supported by the work of Gebbie
(1999) who states that professional nurses need a minimum basic awareness and skills for dealing with organizational and policy issues. An increased understanding of how systems, policies, and populations are related and how they can be used to improve health outcomes (Milio, 2002) should be a goal for graduate nursing education.

Many existing program goals for advanced education in nursing include statements that advanced practice includes practice that influences systems, health-care agencies, political systems, as well as public and professional organizations. Included in the nurses' practice is the goal to transform these systems to facilitate expertly designed nursing interventions (National Association of Clinical Nurse Specialists, 2004). The difference is that the emphasis of the program remains in developing the practitioner to achieve clinical expertise in a specialty and to use their knowledge of health-care policy to facilitate their interventions. Knowledge of public policy is used to support this primary goal rather than being the primary goal as suggested by Milio (2002). When health-care policy becomes the focus, it is the policy that shapes the interventions, including situations where policy change is needed.

Another curriculum focus needed to be developed at the expert level is the development of strategies that improve the quality of care while managing costs. It has long been established that improvements in health services to any given population is aided when programs are efficiently and effectively developed and managed. To do so, nurses must be capable of defining the characteristics of a given population and establishing the parameters of what type of health improvement strategies would be appropriate (McAlearney, 2003). Nurses, to be effective, need skills in advanced management, marketing, integrated information technologies, resource allocation, finance, legal, and organizational politics. Nurses with advanced business degrees traditionally have mastery of these skills but typically they have not been developed synergistically with concepts related to health-care policy or population-focused care.

\section{Population Health or Population-focused Care}

Population health continues to remain a concept that needs to be developed at an expert nurse level. Population health prepares the graduate nurse to develop and implement strategies that can either focus on health promotion or lifestyle to improve 
health habits or focus on a particular disease or condition and the spectrum of services needed for the coordination of their care needs in an efficient and cost sensitive manner. Population health is in keeping with recommendations from Healthy People 2010 (U.S. DHHS, 2000), National League for Nursing (1992), the Institute of Medicine (1996), Robert Wood Johnson Foundation (2000), and the Pew Commission (1991) that nurses be prepared to function in multiple settings both within and beyond institutions to respond to the current shift in health care from inpatient to community-based care. The former president of Sigma Theta Tau is quoted as saying, "Only by transforming nursing education and practice can we hope to introduce graduates who are prepared to meet the expectations of populationbased health-care systems" (Robert Wood Johnson Foundation, 2000, p. 46).

As early as 1979, the U.S. DHHS published reports that indicated that human behavior and environmental factors greatly affected health outcomes and called for experts to be educated that could design and manage strategies aimed at reducing the influence of these factors on negative health outcomes. Population health care became more global than population-focused care in that the emphasis was altering lifestyle behaviors that contributed to poor health that would be implemented and managed at any point in time and across all health-care services. The goal was to identify predisposing, enabling, and reinforcing factors to these behaviors and implement strategies to reduce habituation or relapse and recidivism of the behaviors. Included in the population health nurse expert's advanced skills was the ability to do an in-depth assessment of the biological, psychological, environmental, and social determinants of the behavior that had strong cultural, social, legal, environmental, or biological bases and the ability to do an in-depth analysis and evaluation of the health-care system's ability to impact the problem.

\section{Population-focused Care}

The need for population-focused care is not a new concept. Population-focused care concentrates on health promotion and disease prevention of aggregates of individuals and has long been the backbone of community health and public health nursing programs. The clinical specialists who graduate from these programs have knowledge of epidemiology, demographics, biometrics, environmental health, community structure, and public policy and can engage in research that advances community practices and health policy development.

The need for such programs has been evident since 1890, when Lillian Wald called upon policy makers to improve the health conditions for those living in the New York slums (Frachel, 1988). Since then, public health and community health nurse specialists as well as state and local health department workers have devoted their services to improve the health care of specific groups of people or communities. Although population-focused care has moved the approach to health care beyond the needs of individuals and families, the goal of populationfocused nursing in Community and Public Health is still to promote healthy communities (Quad Council on Public Health/Community Health Nursing, 1999). As such, there remains the need for nurses who are educated to cross institutional lines and develop and manage health strategies within a given population in all environments and at any point in the health continuum.

\section{Is This Realistic?}

The development of a curriculum that educates a nurse to be an expert clinical leader needs to synthesize the skills of a clinical specialist with a business expert who has a strong health-care policy background and is population-focused. Is it realistic to achieve such a worthy goal at the mater's level or is the reason that nursing graduate programs have separated these skills into distinct areas and produced so many divergent experts is that expert skill with more than one focus is beyond master's education? It may be that the goal is attainable provided the focus is clear.

\section{The Future of Master's Education in Nursing}

To meet the growing need for professional nurses with these advanced skills, there appears to be two similar models on the horizon. One is the population nurse expert and the other is the CNL. Both models produce a generic nurse expert who synthesizes clinical expertise with care management skills for individuals, cohorts, or aggregates across all health-care settings. These models stand apart from more traditional graduate programs in that the primary focus is not to produce a nurse with advanced clinical expertise in a specialty area or 
administration but rather one who provides lateral integration of care services within a system of care to affect quality, client care outcomes (AACN, 2004). The CNL refers more to microsystem care, whereas the population health nurse expert expands from microsystems to macrosystems.

The population health nurse expert curriculum has been enacted in several schools of nursing in recent years including the master's program at Cleveland State University (CSU). Cleveland State School of Nursing designed a curriculum to educate nurses to become specialists in population health practice by expanded by the precede-proceed model (Green \& Kreutner, 1991) and the concepts of stressors, stress, general resistance resources, and diseases of adaptation, which provide the conceptual and organizing framework for CSU's undergraduate program. The core curriculum is supported by nursing knowledge enhanced by coursework in theory, research, ethics, policy, finance, and role development. The curriculum is designed to move the student from knowledge acquisition in Phase 1 of the program to practice application in Phase 2. Phase 1 courses present students first with introductions to the practice of population health and to provide knowledge of the theories that inform care. Recommended graduate-level core courses and content such as nursing theory, research, ethics, diversity, nursing roles, and leadership are included in this phase. These courses prepare students to critique, evaluate, and utilize appropriate theory and to learn the basic skills of research and population assessment. Phase 2 places students in actual clinical/field contact with their populations. In this phase, students appraise and evaluate the influence of finance and public policy factors in relation to the health-care decisions and health outcomes of populations. The students culminate their education by implementing a research or quality assurance project that impacts the health-care outcomes of their population of focus (CSU, 2001).

The unique focus of the curriculum allows the student to study models of health-care policy as well as principles for understanding behavior of complex health care, social organizations, community groups, and subcultures. Coursework in health-care policy assists the student to address issues related to managed care, program planning, resource allocation, utilization and outcomes, and government and business influences on population health nursing practice. Health-care financing focuses the student learning experiences on strategic thinking for planning and managing in health-care settings. Econom- ics, reimbursement, budget planning, business planning, and marketing are explored in relation to nursing services (Frisch et al., 2003).

Examples of student synthesis of the population health concepts include projects such as the development of competencies that impact the sexual decision making of adolescents in high schools and outcome evaluation programs for ventilator dependent patients. One student, using the precede-proceed model, was able to work with the area Healthy Family, Healthy Start Programs to design assessment and intervention programs for adolescents based on data from the school's databases. She worked on a permanent planning committee of the school to evaluate the outcomes of these interventions. The design of the intervention program required advanced skill at the graduate level in demography, data analysis, data projections, growth and development, ethics, culture, and decision-making. Another student evaluated the outcomes of care provided to populations of ventilator dependent persons in a rehabilitation facility. This required evaluation of clinical protocols, staffing mix, patient outcomes, costbenefit analyses, as well as ability to apply nursing, developmental, physiological, and pharmacological knowledge to the population (CSU, 2001).

\begin{tabular}{|c|c|}
\hline CNL “Ten Assumptions” & Population Health Expert \\
\hline $\begin{array}{l}\text { Practice is at the microsystems } \\
\text { level. }\end{array}$ & Practice is at the macrosystems level. \\
\hline $\begin{array}{l}\text { Client care outcomes are the } \\
\text { measures of quality practice. }\end{array}$ & $\begin{array}{l}\text { The improvement of clinical outcomes } \\
\text { while maintaining cost effectiveness is } \\
\text { the measure of quality practice. }\end{array}$ \\
\hline $\begin{array}{l}\text { Practice guidelines are based } \\
\text { on evidence. }\end{array}$ & $\begin{array}{l}\text { Practice is based on evidence and } \\
\text { research. }\end{array}$ \\
\hline $\begin{array}{l}\text { Client centered practice is } \\
\text { intra/interdisciplinary. }\end{array}$ & $\begin{array}{l}\text { Practice is population-centered and } \\
\text { is intra/interdisciplinary across } \\
\text { health-care systems. }\end{array}$ \\
\hline $\begin{array}{l}\text { Information will maximize } \\
\text { self-care and client } \\
\text { decision-making. }\end{array}$ & $\begin{array}{l}\text { Attitudes, values, behaviors, and } \\
\text { lifestyle will enhance self-care. }\end{array}$ \\
\hline $\begin{array}{l}\text { Nursing assessment is the basis } \\
\text { for theory and knowledge } \\
\text { development. }\end{array}$ & $\begin{array}{l}\text { Nursing process including assessment } \\
\text { (precede-proceed model) is the basis } \\
\text { for theory and knowledge } \\
\text { development. }\end{array}$ \\
\hline $\begin{array}{l}\text { Good fiscal stewardship is a } \\
\text { condition of quality care. }\end{array}$ & $\begin{array}{l}\text { Evaluation of the health-care system } \\
\text { is essential for quality care. }\end{array}$ \\
\hline $\begin{array}{l}\text { Social justice is an essential } \\
\text { nursing value. }\end{array}$ & $\begin{array}{l}\text { Health-care policy is integral to } \\
\text { health strategies. }\end{array}$ \\
\hline $\begin{array}{l}\text { Communication technology } \\
\text { will facilitate the continuity } \\
\text { and comprehensiveness } \\
\text { of care. }\end{array}$ & $\begin{array}{l}\text { Care strategies across systems rely on } \\
\text { use of all communication techniques. }\end{array}$ \\
\hline $\begin{array}{l}\text { The CNL must assume } \\
\text { guardianship for the } \\
\text { nursing profession. }\end{array}$ & $\begin{array}{l}\text { Population nurse expert will } \\
\text { collaborate with all nurses to } \\
\text { advance the nursing profession. }\end{array}$ \\
\hline
\end{tabular}


The development of CNL graduate curriculum is currently being developed in association with the AACN by several schools of nursing and their practice partners across the United States. The model is based on "Ten Assumptions" developed by the AACN and calls for a liberal educational base as the framework for the curriculum (AACN, 2004). Although it is recognized that individual programs will vary, CNL curriculum must include a strong base in the physical and social sciences as well as learning experiences in philosophy, the arts, and humanities. The AACN recommends including courses in economics, environmental science, epidemiology, genetics, gerontology, global perspectives, informatics, organizations, systems, and communications (AACN, 2004). Core competencies in critical thinking, communication, assessment, technology and resource management, health promotion, risk reduction, and disease prevention will be acquired over the course of the program and will move the student from simple applications to more complex levels of integration (AACN, 2004). This model parallels the population health model in several ways.

\section{What Do These Models Add to the Profession of Nursing?}

Nursing has traditionally separated management from service. Patient care is in the hands of clinicians that follow a hierarchy ranging from staff nurse to advanced practice nurse. Care is provided at the bedside by a nurse who is typically supervised by someone in management, usually a head nurse or supervisor. Patients requiring more than routine care may have their needs met by an array of different advanced practice nurses. These nurses typically report to directors of vice presidents of nursing who may or may not be expert clinicians themselves. Coordination of the patients care needs may come from the attending physician, head nurse, charge nurse, discharge coordinator, case manager, or an advanced practice nurse. If the patient enters another part of the health-care system, an entirely different set of individuals is often involved. As health-care has become more intricate and complex, nursing has become more specialized in an effort to retain expertise in all sectors. Those who give the expert care seldom supervise or evaluate the care given by others. Those in administrative positions responsible for development of cost effective quality care programs seldom give direct patient care. Even more unlikely is that there is someone who develops, manages, or evaluates quality cost effective care across unit or institutional lines on a regular basis. The current system reduces the likelihood that the long-range needs of patients, especially those involving lifestyle, are being addressed, that effective care programs are being maintained, and those that are ineffective, duplicative, or inefficient eliminated. What is missing is the nurse who assumes a horizontal leadership role, the nurse who can cross unit lines to organize, manage, or supervise care for given populations across their life span, the nurse who looks at medication errors and says what kind of policy is needed to prevent these and how he or she can go about having it enacted. What these roles provide for nursing is the closing of the specialty circle while insuring quality cost effective care.

\section{Conclusions}

Programs in graduate education in nursing need to support the evolving needs of the complex healthcare system and the anticipated health-care dilemmas of the future. Nontraditional programs need to be developed that allow nurses to obtain analytical skills beyond the traditional specialty practice areas and develop expertise in improving health-care outcomes for populations across the health-care continuum in a cost effective manner. Two very similar models are evolving to meet this need. It is important that the profession of nursing support these efforts and not be hindered by criticism that additional roles are unnecessary or even detrimental.

\section{References}

American Association of Colleges of Nursing. (1993). Position statement: Nursing education's agenda for the 21st century. Washington, DC: Author.

American Association of Colleges of Nursing. (1996). The essentials of master's education for advanced practice nursing. Washington, DC: Author.
American Association of Colleges of Nursing. (2004). Working paper on the role of the clinical nurse leader. Washington, DC: Author.

Buerhaus, P., Staiger, D., \& Auerbach, D. (2000). Implications of an aging registered nurse workforce. Journal of the American Medical Association, 283, 22. 
Cleveland State University. (2001). Self study report. Cleveland, OH: Author.

Conrad, C., Haworth, J., \& Miller, S. (1996). A silent success: Master's education in the United States. Balti more, MD: John Hopkins University Press. In American Association of College of Nursing, (Ed.), The essentials of master's education for advanced practice nursing. Wash ington, DC: Author.

Consortium awarded to: Robert Wood Johnson Foun dation. (2000). Grant to develop nursing practice model. Legislative Network in Nursing, 46.

Donahue, J. (1997). Disunited States. New York: Basic Books.

Frachel, R. (1988). A new profession: The evolution of public health nursing. Public Health Nursing, 5, 8690.

Frisch, N., George, V., Govoni, A., Jennings Sanders, A., \& McCahon, C. (2003). Teaching nurses to focus on the health needs of populations. Nurse Educator, 28, 212216.

Gebbie, K. (1999). The public health workforce: Key to public health infrastructure. American Journal of Public Health, 89, 660661.

Green, L., \& Kreutner, M. (1991). Health promotion planning. An educational and environmental approach. Mayfield, CA: Mountainview.

Institute of Medicine. (1996). 2020 Vision: Health care in the 21st century. Institute of Medicine 25th Anniversary Symposium Washington, DC: Author.
Institute of Medicine. (2003). Health professions education: A bridge to quality. Washington, DC: National Academies Press.

Kimball, B., \& O’Neill, E. (2002). Health care's human crisis: The American nursing shortage. Princeton, NJ: The Robert Wood Johnson Foundation.

McAlearney, A. (2003). Population health management: Strategies to improve outcomes. Chicago: Health Adminis tration Press.

Milio, N. (2002). Building capacity for policy action: Educating today's and tomorrow's nurses. Journal of Nursing Law, 8, 715.

National Association of Clinical Nurse Specialists. (2004). Statement on clinical nurse specialists practice and education. Harrisburg, PA: Author.

National League for Nursing. (1992). An agenda for nursing education reform: In support of nursing's agenda for health care reform. New York: Author.

Pew Foundation. (1991). Healthy America: Practitioners for 2005. Durham, NC: Author.

Quad Council on Public Health/Community Health Nursing. (1999). Scope and standards of public health nursing practice. Washington, DC: American Nurses Association.

Safriet, B. (1992). Still spending dollars, still searching for sense: Advanced practice nursing in an era of regulatory and economic turmoil. Advanced Practice Nursing Quarterly, 4, 2433.

U.S. Department of Health and Human Services (2000). Healthy people 2012. Washington, DC: U.S. Government Printing Office. 